\title{
Nova Vida para as Línguas Mortas
}

\section{New Life for Dead Languages}

O alpha parece um "a", e tem som de "a", mas se você não tomar cuidado na hora de escrever, ele fica parecendo um 2 . O beta é fácil: um B com a perna comprida. Até o som é o mesmo. Em grego, existem dois “o”, o ômicron, que é um "o" curto, e o ômega, que é um "oooooo", e é meio difícil saber quando usar cada um.

Esses são alguns dos desafios encontrados pelas turmas do sexto e sétimo ano da Escola Municipal de Ensino Fundamental Desembardador Amorim Lima, ou só "Amorim" para os estudantes e funcionários. Os alunos dessas turmas têm aulas de grego antigo uma vez por semana como parte de sua grade horária. Eles não são os únicos a ter contato com uma língua antiga: seus colegas do quarto e quinto ano também têm aulas de latim, com a mesma frequência.

Essas disciplinas são ministradas por monitores bolsistas e voluntários da USP que participam do Projeto Minimus, ano II: O Grego e o Latim no Ensino Fundamental. Coordenado pela professora Paula Corrêa, da Faculdade de Filosofia, Letras e Ciências Humanas (FFLCH), esse projeto de extensão se baseia em estudos realizados nos Estados Unidos que mostram que o ensino dessas línguas para alunos do ciclo fundamental são "uma forma de aperfeiçoar a proficiência dos alunos na língua materna, de facilitar o aprendizado de outras línguas estrangeiras e de desenvolver o raciocínio lógico e o pensamento crítico".

Segundo Fernando Gorab, aluno da graduação em latim e um dos monitores que participam do projeto, essa ideia teve origem em locais como os Estados Unidos e Inglaterra, que tinham um ensino de base clássica, que incluía grego e latim antigos, mas que foi sendo modificado. Com essa modificação, a falta dessas línguas começou a se fazer notar. "Tem um impacto no rendimento dos alunos na parte de línguas e também na parte de exatas, porque como são línguas declinadas, o aprendizado delas ajuda no pensamento lógico", diz.

\section{Gustavo Sumares} Universidade de São Paulo. Escola de Comunicações e Artes, São Paulo, Brasil 


\section{A ESCOLA}

Localizada próxima da USP, a Amorim desenvolve um projeto pedagógico bastante diferente do ensino tradicional: os alunos são separados em turmas com o nome de cores em vez de serem divididos rigidamente de acordo com o ano em que estão. As salas não possuem carteiras enfileiradas, mas mesas e cadeiras que podem ser organizadas em diferentes formatos, conforme as exigências da atividade proposta ou a vontade dos alunos. Os professores não dão sempre aulas expositivas intercaladas de exercícios, mas vão passando entre os grupos de estudantes, acompanhando seu desenvolvimento e auxiliando-os de maneira mais pessoal.

Um dos fatores que levou o projeto a se instalar na Amorim foi essa abertura da escola para propostas pedagógicas diferentes do ensino tradicional. Paula Corrêa, a coordenadora do projeto, conta que a diretora da Amorim, Ana Elisa Siqueira, foi extremamente receptiva com a ideia: "Quando eu comecei a falar, ela ficou encantada com o projeto. Ela até falou 'nossa, que luxo! Grego e latim para os nossos alunos!"”.

Essa disposição por parte da direção fez com que o projeto tomasse um rumo diferente do planejado: "a minha ideia inicial era dar aulas extracurriculares, para quem quisesse. Uma de grego, uma de latim”, explica Paula. No entanto, por sugestão de Ana, as duas disciplinas foram colocadas na grade curricular dos alunos.

Essa mudança colocou alguns desafios para o projeto. Segundo a coordenadora do projeto, eram ao todo 250 alunos que deveriam ter aulas, duas vezes por semana, nos períodos da manhã e da tarde. Foi possível fazer frente a essa demanda com a ajuda de bolsistas e voluntários, alunos da graduação e da pós-graduação, orientados de Paula e de colegas dela, que montaram uma equipe dedicada à tarefa. As bolsas vêm da Pró-Reitoria de Cultura e Extensão da USP e da Fundação Onassis, uma fundação privada de benefício público sediada em Liechtenstein, criada pelo empresário grego Aristóteles Onassis para disseminar informação e o conhecimento da civilização helênica pelo mundo.

As atividades de Paula tiveram início em 2013. Naquele ano, os alunos do quarto ano tiveram aulas de latim e os do sexto ano, de grego antigo. As aulas foram bem recebidas, tanto pelos alunos quanto pelos outros professores e coordenadores da Amorim. A escola, no final de cada ano, realiza uma Festa da Cultura, para a qual os alunos preparam atividades culturais em torno do estudo de uma determinada cultura.

Por conta das aulas de grego e latim, a escola dedicou a Festa de Cultura de 2013 à Antiguidade

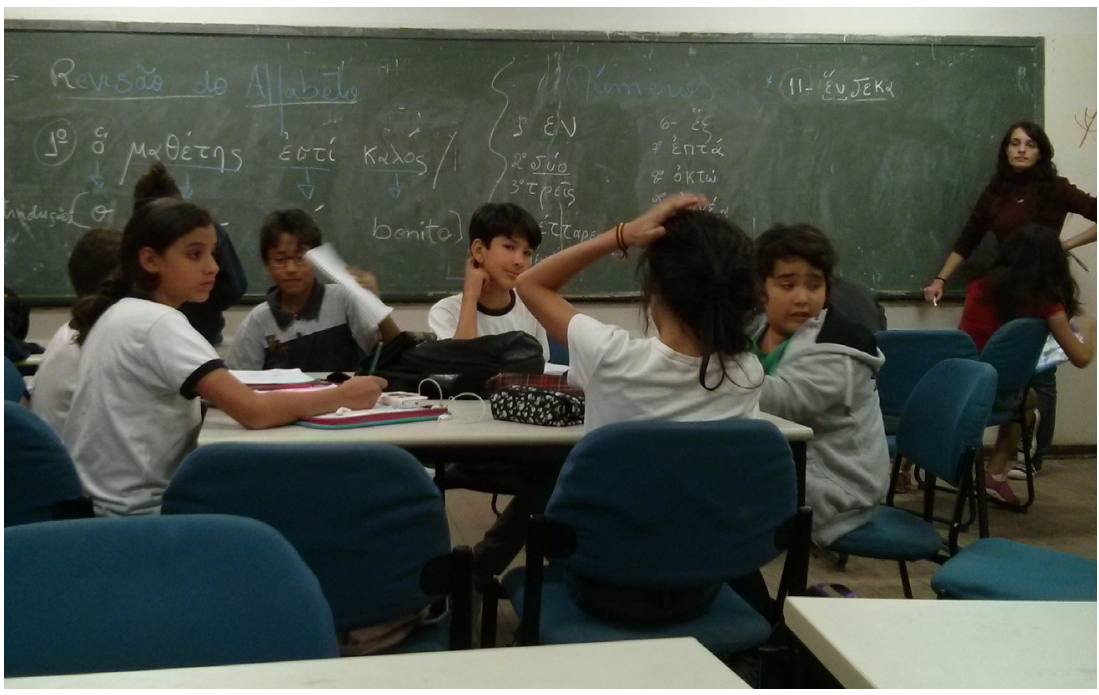

Figura 1 - Para aprender o grego, os alunos realizam transliterações de frases em português. 

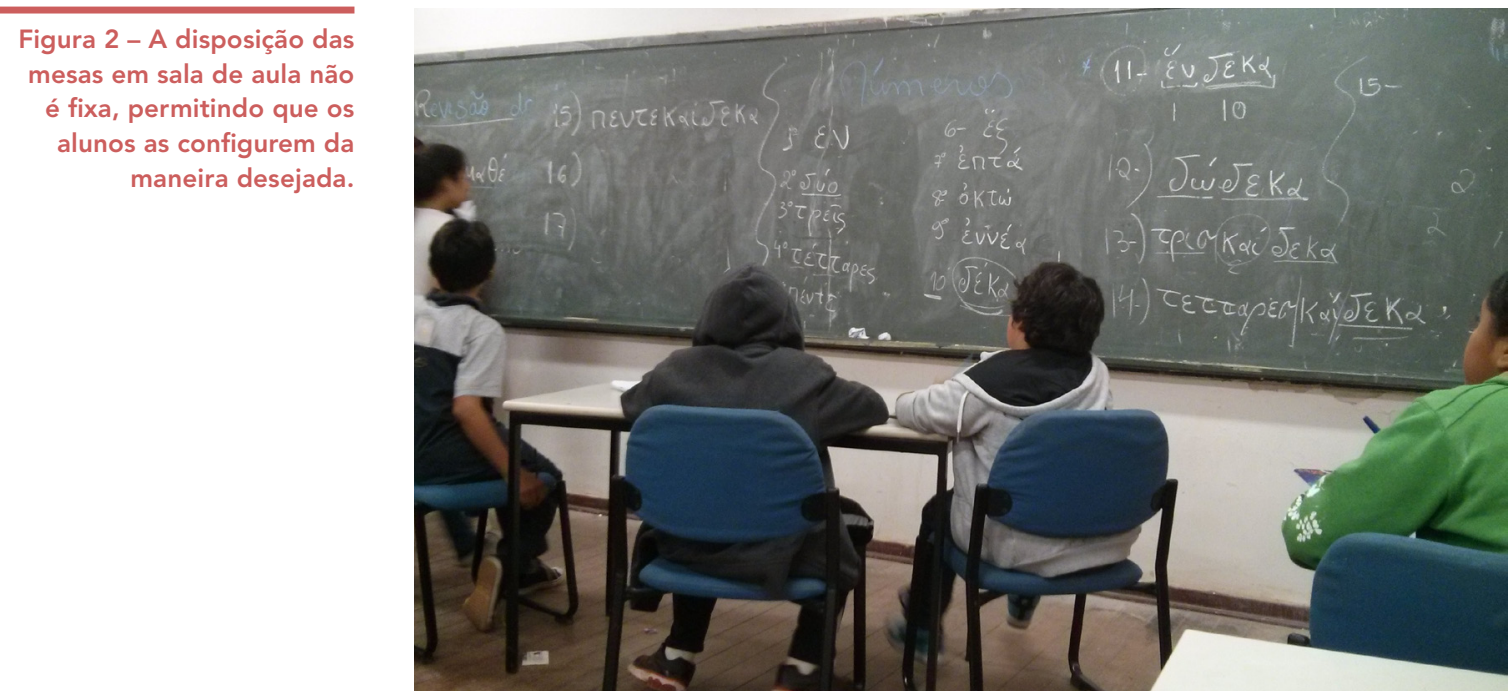

Clássica, ou seja, às culturas grega e romana. "A escola ficou cheia de projetos sobre Grécia e Roma, em todas as esferas: ciências, matemática, geografia, geometria, literatura, artes", conta Paula. As turmas da tarde chegaram inclusive a desenvolver dois projetos de artes cênicas, um deles baseado em Antígona, de Sófocles, e o outro na história do Minotauro. "A gente passou algumas frases da peça para o grego, e aproveitou para escrever algumas coisas em grego no cenário, como 'Labirinto de Creta', que eram coisas que eles já podiam fazer", conta Silvia Anderson, aluna de doutorado e monitora do projeto.

Graças a essa boa recepção, o projeto teve continuidade em 2014: além de receber novas turmas de latim e grego antigo, os alunos que haviam estudado no ano passado tiveram a opção de continuar seus estudos.

\section{PROJETO}

O nome do projeto vem do método Minimus, uma série de livros escolares dedicados a ensinar latim a alunos do ensino fundamental, publicado pela Cambridge University Press. O personagem principal dos livros é um rato chamado "Minimus" (a palavra latina que significa "o menor", mas também um trocadilho, já que "mus" em latim significa rato).
Além do ratinho, o livro apresenta os alunos a uma família, composta por Flavius, sua esposa, seus três filhos, seus escravos e seu gato. Essa família é livremente inspirada numa família que realmente viveu na região de Vindolanda por volta do ano 100 antes de cristo (a época e a região em que a história se passa), e essa história familiar mistura eventos reais com narrativas fictícias inventadas pela autora Barbara Bell. "Eu escrevi para a autora e consegui a autorização dela para traduzir e usar como teste”, afirma Paula, que considera o Minimus um "método ideal para essa faixa etária”.

Mesmo assim, no entanto, algumas modificações foram necessárias. "Os alunos, quando chegam para as aulas de latim, ainda não aprenderam classes gramaticais, uma coisa que o material [o Minimus] exige. Então a gente desenvolveu atividades extras que cobrissem essas diferenças do currículo, e a partir daí a gente conseguiu organizar uma apostila para o segundo ano do projeto", conta Fernando.

Os monitores de língua grega encontraram mais obstáculos nesse aspecto, já que o ensino dessa língua para alunos dessa idade não possui ainda um método igualmente satisfatório. Silvia conta que eles chegaram a trabalhar com um sistema de ensino chamado Athenazde, da Cambridge University Press, voltado para alunos do ensino médio, mas acabaram achando-o inadequado para 
os alunos. "Embora fosse mais fácil e acessível, os textos não eram muito atrativos", conta Paula. Por conta disso, os monitores encarregados das aulas de grego precisaram ir criando um método conforme as aulas evoluiam, adaptando seus métodos conforme a receptividade dos alunos. "Em 2013, a gente teve que se esforçar um pouco mais, porque a gente tinha que preparar muitas das atividades de aula. Como esse é o segundo ano, já está mais tranquilo", comenta Silvia.

$\mathrm{O}$ que torna o grego antigo e o latim línguas diferentes, além de sua importância para a nossa cultura, é o fato de que essas línguas são declinadas: nelas, as palavras se transformam segundo sua função sintática. Assim, uma frase pode ser escrita em qualquer ordem já que as palavras já trazem em si seu papel de sujeito, objeto, etc. Algumas línguas atuais, como o russo e o alemão, também são declinadas. Não seria mais interessante, portanto, ensinar essas línguas aos alunos? Segundo Paula, os resultados não são os mesmos: "Fizeram estudos com outras línguas declinadas e, por alguma razão desconhecida, o estudo do grego e do latim ajuda mais [no desenvolvimento dos alunos em outras áreas] que o do russo e do alemão".

\section{AS AULAS}

Graças à metodologia diferente da Amorim, as aulas são bem mais dinâmicas do que o normal. Os alunos chegam na sala e, em vez de se sentar organizadamente em cadeiras enfileiradas, conversam com os amigos e vão se arrumando em mesas espalhadas pela sala sem uma regra claramente definida. Se sentem vontade, podem mudar suas mesas de posição, ir sentar em outro lugar ou mesmo ficar em pé por algum tempo. Como resultado, os alunos não ficam constantemente voltados para a lousa, mas isso não é um problema: embora os monitores a utilizem para escrever a matéria e os exercícios, eles passam a maior parte do tempo indo de grupo em grupo para acompanhar de forma mais próxima o desenvolvimento dos alunos.
Em média, cada monitor fica responsável por seis alunos, o que significa que há sempre mais de um monitor na sala de aula. Eles não chegam a ser figuras tão centrais na sala quanto o método tradicional de ensino nos leva a esperar de um professor, e a principal impressão que isso deixa em quem vê é de que o aluno é, de fato, o centro das aulas.

Uma pessoa acostumada ao método de ensino tradicional pode achar esse esquema um pouco bagunçado e desorganizado. No entanto, os professores percebem nesse arranjo algumas vantagens: "Eles [os alunos] têm liberdade para seguir o seu próprio ritmo e, como nós somos vários professores na sala de aula, nós conseguimos atender os alunos de uma forma mais próxima”, diz Fernando.

Para Érika Pasquali, que ministra aulas de grego, foi um pouco chocante se adaptar a esse ambiente diferente. "Eu aprendi, como aluna e como professora, a lidar com uma turma grande e a trabalhar com lousa, aulas expositivas, e na Amorim você trabalha com grupos pequenos que exigem muita atenção, porque eles estão acostumados a um professor que vai até eles tirar as dúvidas", comenta ela. Outro aspecto que lhe pareceu diferente na metodologia da Amorim foi a hierarquia: "os alunos se vêem como iguais a todos, então ele tratam as coordenadoras e diretoras informalmente, como se fossem colegas mesmo", conta ela.

Por conta dessas diferenças e, no caso do grego, devido à falta de um método de ensino adequado para aqueles alunos, os monitores tiveram um trabalho significativo de adaptação. "Nós precisamos descobrir como tratar os alunos da forma individual a que eles estavam acostumados e, ao mesmo tempo, conseguir atender um grupo grande”, conta Érika.

Com o tempo, porém, eles foram descobrindo formas interessantes de ensinar essas línguas antigas aos alunos utilizando exemplos do cotidiano deles. "Esse ano, a gente trouxe frases em grego que os alunos poderiam usar agora. Diálogos como 'Oi, meu nome é tal, gosto disso, daquilo'. São frases em grego antigo, mas que eles poderiam usar agora”.

Segundo os monitores, fazer com que os alunos se interessem por línguas "mortas" é um desafio 
menor do que parece. "A gente não lida com essas línguas como línguas mortas. Aqui, a gente tenta trazer o que essas línguas têm de semelhantes. $\mathrm{O}$ português não é mais latim, mas a gente consegue mostrar como as palavras eram e como elas ficaram, e eles mesmos vão percebendo o que é parecido", conta Fernando. Segundo Paula, "eles não vêem essas línguas como línguas mortas. Acho que até demora um pouco para eles perceberem que aquilo não se fala na Grécia e na Itália”.

O alfabeto grego, apesar de ser um pouco chocante no primeiro contato, não causa muitos problemas aos alunos. "Até eu quando peguei o alfabeto achei assustador", conta Érika, "mas depois você vai vendo que ele é muito parecido com português, e eles pegam facilmente. E eles adoram escrever o nome em grego", diz. Paula acrescenta também que "as crianças dessa idade gostam de ter um código secreto, alguma coisa que os distingue dos outros. E o grego e o latim acabam virando esse código, porque as outras professoras não sabem o que eles estão falando. Então eles escrevem bilhetinhos uns para os outros, e se apropriam disso".

Além disso, segundo Paula, "eles têm um conhecimento da mitologia muito maior do que a gente imagina”. Os alunos têm um contato relativamente inesperado com a língua e a mitologia grega graças à sua presença em alguns livros e filmes, como a série Percy Jackson (cujo personagem principal é filho do deus grego Poseidon), e jogos de videogame como a série God of War (cujo protagonista, um capitão do exército de Esparta, torna-se servo do deus Ares após ter sua vida salva por ele). "A língua traz várias dificuldades, mas a gente vai equilibrando com essa parte, da qual eles gostam muito", conta Silvia.

A impressão dos envolvidos no projeto é que o "preconceito" que nós temos com o aprendizado de línguas que não têm uma utilidade imediata é algo que aqueles alunos felizmente ainda não têm. Para Fernando, "A aceitação deles é muito melhor do que seria a nossa, por exemplo. São pouquíssimos que vêm perguntar 'por que que eu estou aprendendo uma língua morta?'. A maioria não têm um preconceito de que a gente só precisa aprender o que é 'útil' num sentido funcional".

Segundo Paula, uma das principais vantagens do projeto na Amorim é o fato de que "são crianças que têm diversas dificuldades e que se vêem beneficiadas de um conhecimento que mesmo os alunos de escolas particulares em geral não têm”. "Eu acredito no projeto como uma forma de melhorar o desenvolvimento pessoal dos alunos", diz Érika.

GUSTAVO SUMARES graduando em Jornalismo da Escola de Comunicações e Artes da Universidade de São Paulo (ECA-USP) e repórter da Revista Cultura e Extensão USP - e-mail: gsumares@gmail.com 